University of Wollongong

Research Online

Faculty of Engineering - Papers (Archive)

Faculty of Engineering and Information

Sciences

$1-1-2009$

\title{
Long-term performance of a permeable reactive barrier in acid sulphate soil terrain
}

Gyanendra Regmi

University of Wollongong, gr524@uowmail.edu.au

Buddhima Indraratna

University of Wollongong, indra@uow.edu.au

Long Nghiem

University of Wollongong, longn@uow.edu.au

Follow this and additional works at: https://ro.uow.edu.au/engpapers

Part of the Engineering Commons

https://ro.uow.edu.au/engpapers/863

\section{Recommended Citation}

Regmi, Gyanendra; Indraratna, Buddhima; and Nghiem, Long: Long-term performance of a permeable reactive barrier in acid sulphate soil terrain 2009, 409-419.

https://ro.uow.edu.au/engpapers/863

Research Online is the open access institutional repository for the University of Wollongong. For further information contact the UOW Library: research-pubs@uow.edu.au 


\title{
Long-term Performance of a Permeable Reactive Barrier in Acid Sulphate Soil Terrain
}

\author{
Revised Manuscript Submitted to \\ Journal of Water, Air \& Soil Pollution: Focus
}

June 2009

Gyanendra Regmi*, Buddhima Indraratna and Long Duc Nghiem School of Civil Mining and Environmental Engineering University of Wollongong, Wollongong, NSW 2522, Australia

* Corresponding author: Gyanendra Regmi, Email: gr524@uow.edu.au, Ph +61 242213017 


\section{Abstract}

Deep drainage technique utilised for flood mitigation in low-land coastal areas of Australia during the late 1960s has resulted in the generation of sulphuric acid in soil by the oxidation of pyritic materials. Further degradation of the sub-surface environment with widespread contamination of the underlying soil and groundwater presents a major and challenging environmental issue in acid sulphate soil (ASS) terrains. Although several ASS remediation techniques recently implemented in the floodplain of Southeast Australia including operation of gates, tidal buffering and lime injections could significantly control the pyrite oxidation, they could not improve the long-term water quality. More recently, permeable reactive barriers (PRBs) filled with waste concrete aggregates have received considerable attention as an innovative, cost-effective technology for passive in-situ clean up of groundwater contamination. However, long-term efficiency of these PRBs for treating acidic groundwater has not been established. This study analyses and evaluates the performance of a field PRB for treating the acidic water over two and half years. The pilot-scale alkaline PRB consisting of recycled concrete was installed in October 2006 at a farm of southeast New South Wales for treating ASS impacted groundwater. Monitoring data of groundwater quality over a 30 month period were assessed to evaluate the long-term performance of the PRB. Higher $\mathrm{pH}$ value $(\sim \mathrm{pH} 7)$ of the groundwater immediately downstream of the PRB and higher rates of iron $(\mathrm{Fe})$ and aluminium $(\mathrm{Al})$ removal efficiency ( $>95 \%$ ) over this study period indicates that recycled concrete could successfully treat acidic groundwater. However, the overall $\mathrm{pH}$ neutralising capacity of the materials within the barrier declined with time from an initial $\mathrm{pH} 10.2$ to $\mathrm{pH}$ 7.3. The decline in the performance with time was possibly due to the armouring of the reactive material surface by the mineral precipitates in the form of iron and aluminium hydroxides and oxyhydroxides as indicated by geochemical modelling.

Keywords: acid sulphate soil, armouring, groundwater quality, permeable reactive barrier, pyrite oxidation 


\section{Introduction}

In coastal Australia, deposited sulphate from seawater in an iron rich environment of marshy land during post-glacial period (6,500-10,000 years old) had been reduced in an enhanced biological reaction in the presence of easily decomposable organic matter to form iron sulphide concentrations (Pyrites) in the soils (Glamore and Indraratna 2001). This process of pyrite formation can be expressed as:

$$
\mathrm{Fe}_{2} \mathrm{O}_{3}+4 \mathrm{SO}_{4}^{2-}+8 \mathrm{CH}_{2} \mathrm{O}+1 / 2 \mathrm{O}_{2} \rightarrow \underset{(\text { Pyrite })}{2 \mathrm{FeS}_{2}+8 \mathrm{HCO}_{3}^{-}+4 \mathrm{H}_{2} \mathrm{O}}
$$

Due to large scale flood mitigating works (surface drains and floodgates) used for lowering the water table to prevent the land from flooding in low-lying coastal areas of Australia, these pyrites have been oxidised to sulphuric acid which have resulted in acidification and formation of soils commonly named 'acid sulphate soils' (Indraratna and Blunden 1999; Sammut et al. 1994; White et al. 1997). The pyrite oxidation can be expressed as:

$\mathrm{FeS}_{2(s)}+7 / 2 \mathrm{O}_{2(a q)}+\mathrm{H}_{2} \mathrm{O} \rightarrow \mathrm{Fe}^{2+}{ }_{(a q)}+2 \mathrm{SO}_{4}^{2-}+2 \mathrm{H}^{+}$

Ferrous ions could be oxidised to ferric which would be soluble in acidic water at low $\mathrm{pH}$ $(<3.5)$ as shown in Eq 3. It could also be hydrolysed to form insoluble ferric hydroxide at $\mathrm{pH}$ greater than 3.5, further generating more acid as expressed in Eqs 4 and 5:

$$
\begin{aligned}
& \mathrm{Fe}^{I I}+1 / 4 \mathrm{O}_{2}+\mathrm{H}^{+} \rightarrow \mathrm{Fe}^{3+}+1 / 2 \mathrm{H}_{2} \mathrm{O} \\
& \mathrm{Fe}^{I I I}+3 \mathrm{H}_{2} \mathrm{O} \rightarrow \mathrm{Fe}(\mathrm{OH})_{3}+3 \mathrm{H}^{+} \\
& \mathrm{FeS}_{2(s)}+14 \mathrm{Fe}^{I I I}+8 \mathrm{H}_{2} \mathrm{O} \rightarrow 15 \mathrm{Fe}^{2+}{ }_{(a q)}+2 \mathrm{SO}_{4}^{2-}+16 \mathrm{H}^{+}
\end{aligned}
$$


Therefore, after initiation of pyrite oxidation, at low $\mathrm{pH}(<4.5)$ the ferric ion could be reduced by pyrite itself more rapidly than by $\mathrm{O}_{2}$ as shown in reaction 5 (Singer and Stumm 1970; Stumm and Morgan 1970) further generating more acid in the soils. During recharge of groundwater by rainfall, release of acid from the soils has mobilized large amounts of iron and aluminium in groundwater from such ASS (Dent 1992; White et al. 1997). Daily discharge of such acidic effluent with high concentrations of dissolved iron and aluminium in fresh- water system have created the ecological disturbances such as the unnatural sudden death of fish, significant damage to agriculture and aquaculture, clogging of waterway (Åström 1998; Åström and Bjorklund 1995; Dent 1992; Indraratna et al. 2005). As a result, discharge from ASS is an intractable environmental problem of coastal region of Australia which covers approximately 3.5 million hectares of ASS land in Australia.

The initial strategy for rehabilitation of the contaminated drain water was the restoring the phreatic zone above the pyritic layer through the installation of fixed level weirs and decreasing the rate of pyrite oxidation (Blunden et al. 1997; Blunden and Indraratna 2000). Modification of floodgates to allow tidal ingress of brackish creek water could improve the drain water quality by buffering action of carbonate/bicarbonates present in the seawater (Glamore and Indraratna 2004). Both of these approaches could prevent further oxidation of pyrite, but were not able to remediate the existing acidity that was already stored in the soil (Indraratna et al. 2005). Moreover, there was always a risk of flooding for low-lying area with poor drainage and both of these approaches could not improve the groundwater quality.

Conventional treatment by lime neutralization produces large volumes of metal-rich sludge and often involves long-term operating costs (Benner et al. 1999). Alternatively, installation of subsurface alkaline horizontal impermeable barrier such as lime-fly ash injection in several places of the ASS area near to drain could also control the pyrite oxidation and improve the 
groundwater quality within close proximity of the barrier (Indraratna et al. 2006; Mulvey 1993). However, its longevity is uncertain due to several factors such as changes in groundwater flow direction, the amount of the alkalinity generation, armouring of the materials and exhaustion of the materials.

Permeable reactive barrier (PRB) has been widely used for remediation of subsurface pollution and contamination due to its high potential to significantly reduce the cost of treating shallow aquifers in addition to preservation of groundwater. Selection of the best suitable materials for the reactive media is also an important factor for long term performance of the PRB (Gavaskar et al. 1998). Application of alkaline material for improving the groundwater $\mathrm{pH}$ through neutralization reaction has also the potential to remove the dissolved Fe and Al (Golab et al. 2006).Therefore, a more practical and innovative option for in-situ passive rehabilitation of groundwater in ASS is to intercept the contaminated groundwater by installing an alkaline PRB. Recycled concrete has been recommended as one of the suitable reactive media for the $\mathrm{PRB}$ based on the batch test analysis among 24 different types of alkaline materials (Golab et al. 2006).

The acidic water can consume generated alkalinity and limit the ability of the lime to promote the chemical reaction. It is anticipated that rise in $\mathrm{pH}$ due to chemical reaction between the acidic water and lime from cement and bicarbonates from calcareous aggregate present in recycled concrete of the PRB can lead to subsequent precipitation of iron and aluminium hydroxide and oxyhydroxide through the reaction outlined in Eqs 6-10. Thus, there is a threat of decreasing efficiency by armouring of reactive media by those precipitates as the precipitation of ferric oxyhydroxides can also result in generation of acidity (Waybrant et al. 2002) and finally affect the flow path by clogging effects of accumulated precipitates (Sun et al. 2000). In addition, the precipitates described in Eqs 11-13 might be formed during mineral 
dissolution/precipitation due to (a) the interaction of iron with water and carbonates/bicarbonates and (b) the saturation of calcium carbonate in the groundwater with rising pH (Mackenzie et al. 1999).

$$
\begin{aligned}
& \mathrm{Ca}(\mathrm{OH})_{2}+2 \mathrm{H}^{+} \rightarrow \mathrm{Ca}^{2+}+2 \mathrm{H}_{2} \mathrm{O} \\
& \mathrm{Fe}^{3+}+3 \mathrm{H}_{2} \mathrm{O} \rightarrow \mathrm{Fe}(\mathrm{OH})_{3(\mathrm{~S})}+3 \mathrm{H}_{a q}^{+} \\
& \mathrm{Fe}^{3+}+2 \mathrm{H}_{2} \mathrm{O} \rightarrow \mathrm{Fe}(\mathrm{OOH})+3 \mathrm{H}_{a q}^{+} \\
& 2 \mathrm{Fe}^{3+}+3 \mathrm{H}_{2} \mathrm{O} \rightarrow \mathrm{Fe}_{2} \mathrm{O}_{3}+6 \mathrm{H}_{a q}^{+} \\
& \mathrm{Al}^{3+}+3 \mathrm{H}_{2} \mathrm{O} \rightarrow \mathrm{Al}(\mathrm{OH})_{3(\mathrm{~S})}+3 \mathrm{H}^{+}{ }_{(a q)} \\
& \mathrm{Fe}^{2+}+2(\mathrm{OH})^{-} \leftrightarrow \mathrm{Fe}(\mathrm{OH})_{2(\mathrm{~S})} \\
& \mathrm{Fe}^{2+}+\mathrm{CO}_{3}^{2-} \leftrightarrow \mathrm{FeCO}_{3(S)} \\
& \mathrm{Ca}^{2+}+\mathrm{CO}_{3}^{2-} \leftrightarrow \mathrm{CaCO}_{3(S)}
\end{aligned}
$$

Although PRBs have been used widely for remediation of variety of contaminants such as chlorinated organic compounds, chromate, radionuclides and heavy metals (Blowes et al. 2000; Blowes et al. 1997; Gu et al. 2002; McMahon et al. 1999; Puls et al. 1999; Scherer et al. 2000; Vogan et al. 1999), their application for treating acidic groundwater is limited. Only one PRB has been reported in ASS terrain with limestone under oxidising condition (Waite et al. 2002). However, it failed in short period because of rapid armouring and clogging by the precipitates due to the presence of oxidising conditions. As results, its long term performance for curbing groundwater from ASS could not be measured because of the limited available data and failure of existing PRB in early stage. 
In the current study, long term performance of the selected reactive media (i.e. recycled concrete) has been monitored from column test experiment at first stage in order to assess the $\mathrm{pH}$ neutralizing capacity of the materials under controlled flow conditions. Based on the results of the long- term column test, a pilot scale alkaline PRB filled with recycled concrete has been designed and installed in the field under reducing condition and its performance has been monitored for last two and half years. Results of both the column test experiment under controlled flow conditions in the laboratory and pilot scaled PRB installed in the natural field conditions of ASS terrain are presented here.

\section{Materials and Methods}

\subsection{Laboratory Column Test}

Column test experiment was carried out over an extended period to assess the $\mathrm{pH}$ neutralization capacity of the recycled concrete under the controlled environment in the laboratory. The experiment was conducted in a acrylic column (ID $\times \mathrm{L}=5 \mathrm{~cm} \times 65 \mathrm{~cm}$ ) packed with $5 \mathrm{~cm}$ sand sausage and $5 \mathrm{~cm}$ of silica sand at the bottom followed by $50 \mathrm{~cm}$ of crushed recycled concrete, and topped with $5 \mathrm{~cm}$ sand sausage with constant medium range pumping rate of $2.0 \mathrm{~mL} / \mathrm{min}$ using a peristaltic Master Flex pump (Fig. 1). The reactive material used in the column was uniformly graded recycled concrete predominantly in the range between $1.18 \mathrm{~mm}$ and $10 \mathrm{~mm}$ whose chemical analysis is shown in Table 1 . The bottom and top sand sausages separated the reactive media from the influent and effluent ports and prevented the physical clogging by other particles.

The column input solution was simulated acidic water comparable in characteristics to the average groundwater from ASS terrain measured continuously for one and half year in the ASS terrain (Table 2). Based on the flow rate, the retention time for one pore volume (533.7 
$\mathrm{mL}$ ) is $3.70 \mathrm{hrs}$ which is $\sim 26$ times smaller than the retention time for estimated groundwater flow rate of $30 \mathrm{~cm} /$ day in the field.

Figure 1 Column test experiment set up

Table 1 Elementary analysis of major elements of recycled concrete

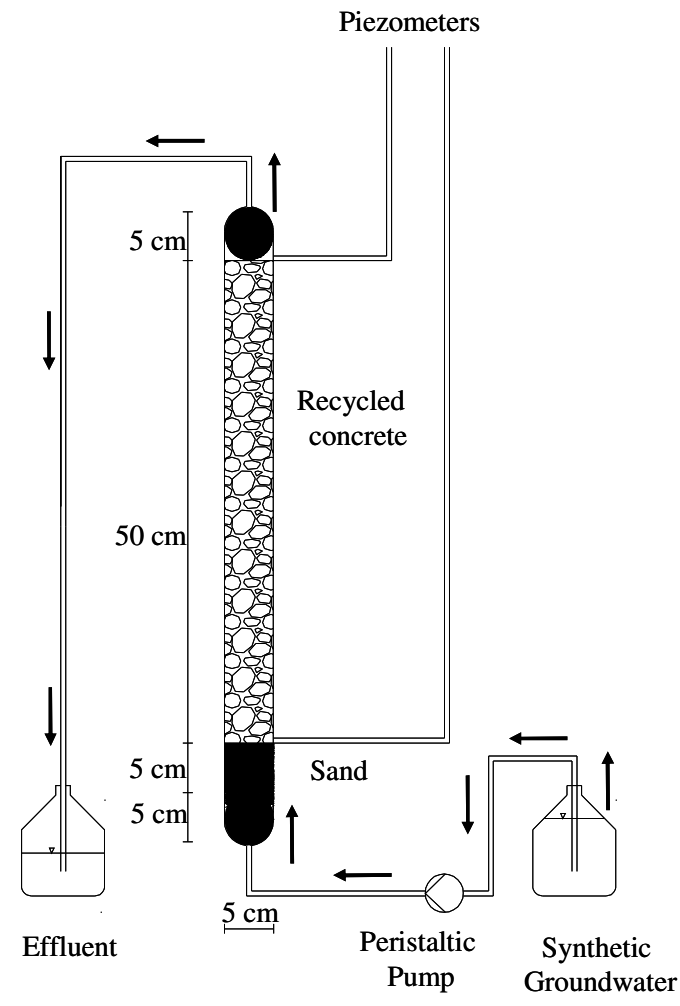

\begin{tabular}{|ll|}
\hline Metals & $\left(\mathrm{mg} \mathrm{kg}^{-1}\right)$ \\
\hline $\mathrm{Ca}$ & 63935 \\
$\mathrm{Mg}$ & 5872 \\
$\mathrm{Na}$ & 413 \\
$\mathrm{~K}$ & 770 \\
$\mathrm{Si}$ & 3416 \\
$\mathrm{Fe}$ & 23909 \\
$\mathrm{Al}$ & 10984 \\
$\mathrm{Cu}$ & 85 \\
$\mathrm{Cr}$ & 31 \\
$\mathrm{Ni}$ & 70 \\
$\mathrm{Zn}$ & 64 \\
$\mathrm{P}$ & 993 \\
$\mathrm{~Pb}$ & 9 \\
$\mathrm{~V}$ & 75 \\
$\mathrm{Mn}$ & 877 \\
\hline
\end{tabular}

Table 2 Comparison of water chemistry of real ASS groundwater and synthetic water for column test

\begin{tabular}{ccc}
\hline Parameters & Groundwater & Synthetic groundwater \\
\hline $\mathrm{pH}$ & $3.75 \pm 0.6$ & 2.7 \\
$\mathrm{Na}^{+}$ & $467.3 \pm 176.2$ & 440 \\
$\mathrm{~K}^{+}$ & $48.4 \pm 11.6$ & 42 \\
$\mathrm{Ca}^{2+}$ & $141.9 \pm 52.7$ & 114 \\
$\mathrm{Mg}^{2+}$ & $147.0 \pm 65.4$ & 90 \\
$\mathrm{Al}^{3+}$ & $18.0 \pm 14.6$ & 40 \\
$\mathrm{Total} \mathrm{Fe}^{-}$ & $137.5 \pm 143.8$ & 83 \\
$\mathrm{Cl}^{-}$ & $815 \pm 270.1$ & 815 \\
$\mathrm{SO}_{4}{ }^{2-}$ & $1312.7 \pm 587.4$ & 1161 \\
\hline
\end{tabular}




\subsection{Pilot scale PRB and monitoring networks}

Following the results of the column test experiments, a pilot scaled PRB $(17.7 \mathrm{~m} \times 1.2 \mathrm{~m} \times$ $3 \mathrm{~m})$ filled with recycled concrete was designed and installed in the acid sulphate soil terrain in south-east New South Wales, Australia in October 2006 running parallel to the flood mitigation drain and intersecting the zone of maximum groundwater flow direction (Fig. 2). A detailed monitoring network consists of 5 rows of monitoring points installed in transect parallel to the groundwater flow and perpendicular to the PRB running from upstream to PRB and downstream direction which includes 36 observation wells, 12 piezometers and 2 dataloggers. Considering the possibility of mixing of untreated upstream groundwater in the upper and lower transects just behind the PRB (Figure 2), the inner three rows a-a, b-b, and cc, out of the five sections are selected to study the performance of PRB with respect to distance travelled.

Figure 2 Layout of the PRB in a farm of acid sulphate terrain in southeast New South Wales

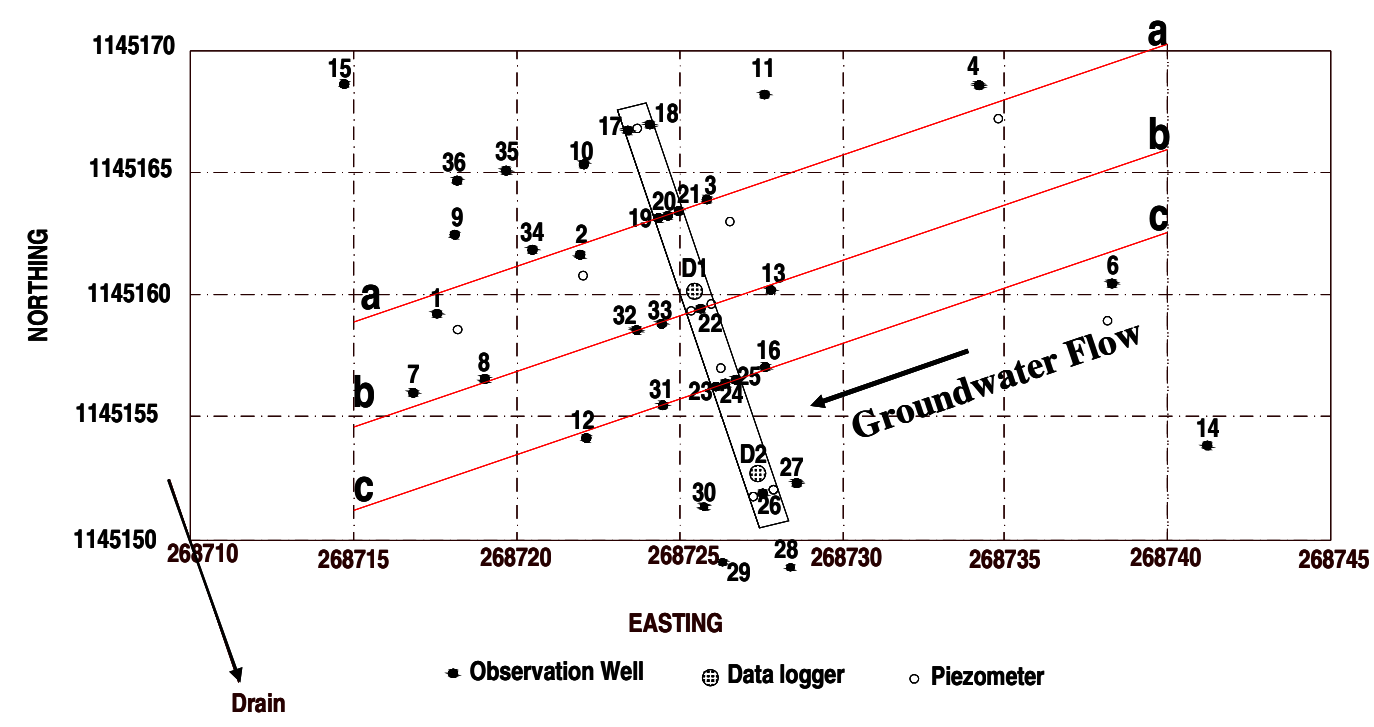




\subsection{Groundwater Quality Analysis}

Water quality parameters including $\mathrm{pH}, \mathrm{EC}, \mathrm{ORP}$ and temperature were monitored using 2 multi-parameter automated data loggers installed inside the PRB and 36 monitoring wells installed in the study area including upstream, inside and downstream of PRB and groundwater elevation from 12 piezometers. In addition, groundwater samples were collected and analysed for major ions including iron and aluminium after 22, 25 and 30 months of installation of the PRB to investigate possible mineral precipitations and their impact on the performance of the PRB. In order to plot the true representation of the water quality from the study area, the longitudinal profiles of these water quality parameters obtained from their contour were plotted based on the data collected from the random distributions of sampling points.

\section{Results and Discussion}

\subsection{Longevity prediction of PRB material from Column Test Analysis}

Long term performance of the neutralizing capacity of the recycled concrete in column test is evaluated by the $\mathrm{pH}$ profile with respect to pore volumes as shown in Figure 3. At the beginning of the tests, $\mathrm{pH}$ increased rapidly due to lime dissolution and decreased with respect to pore volume. In the early stage, $\mathrm{pH}$ decreased rapidly to $\mathrm{pH} 7.5$ within 50 pore volumes due to neutralization reaction between highly acidic water with concrete and was maintained the same value for next 100 pore volumes after which it started to decrease again. This decreasing trend of $\mathrm{pH}$ after reaching the stabilized near neutral value $(\mathrm{pH} \sim 7.5$ ) shows the sign of armouring for reducing the $\mathrm{pH}$ neutralization efficiency due to the precipitation of minerals inside the column which was obvious with visible red and white precipitates on the surface of the aggregates and also within the pore space of the concrete growing from bottom to top of the column. 


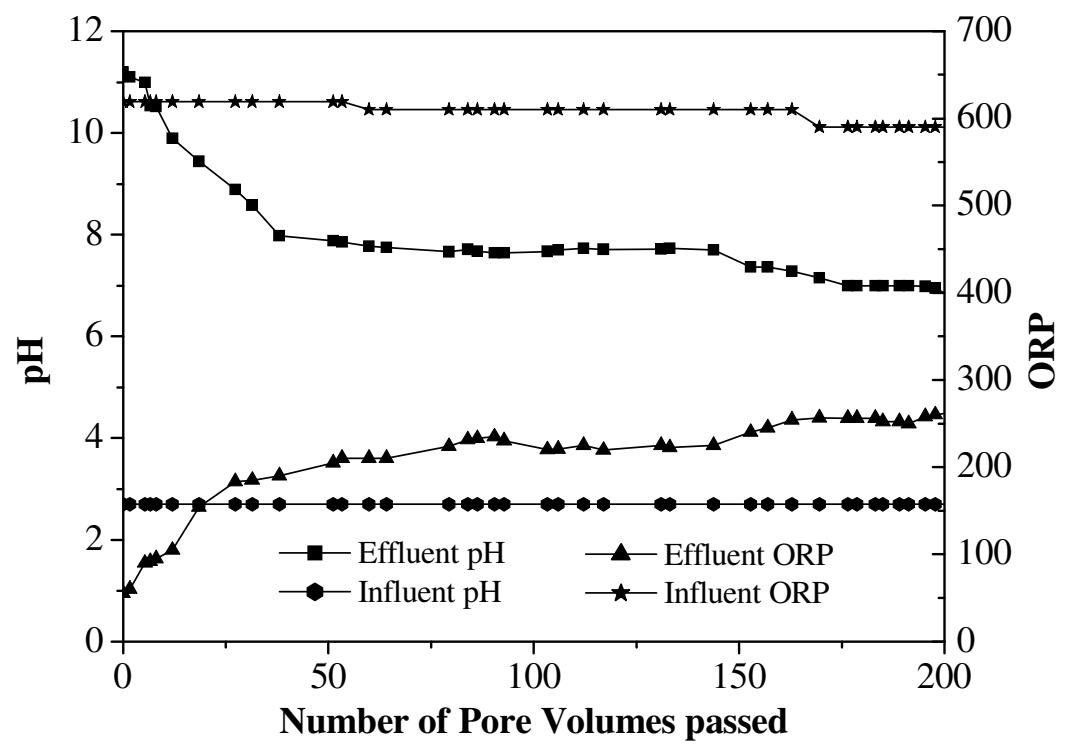

Figure 3 Longevity study of recycled concrete with medium flow rate of $2 \mathrm{~mL} / \mathrm{min}$ in column test experiment

This decreasing $\mathrm{pH}$ profile and increasing trend of ORP indicates the growth of the precipitates from bottom of the column towards upward flow direction inside the column. Although the initial part of the reactive medium gradually lost its efficiency to buffer $\mathrm{pH}$, continuous lime dissolution at the upper parts of the column still added alkalinity in the system over a relatively long period of time for the continuous constant flow rate of synthetic acidic water. Since the residence time for the column test was 26 times lower than that of estimated groundwater in the field, the recycled concrete would take at least 2.2 years with the field groundwater flow rate to reach $\mathrm{pH}$ corresponding to 200 pore volumes measured in the column test provided the similar conditions. In addition, the acidity of the feed solution in this column test experiment ( $\mathrm{pH} \sim 2.68)$ was considerably more acidic than the field condition (average $\mathrm{pH} \sim 3.5$ ). Thus, the efficiency in the laboratory would have been maintained over a much longer period if maintained the same acidity as in field. The results obtained from the column test concludes that recycled concrete is suitable material for long term $\mathrm{pH}$ neutralizing of acidic water because of its longevity in maintaining the near neutral $\mathrm{pH}$ with 
strong acidic water. Based on the result of column test experiment, the material was selected for use in the PRB.

\subsection{Groundwater Quality changes due to PRB}

The improvement of the field groundwater quality by the PRB is illustrated by the $\mathrm{pH}$ and ORP profile (Figure 4). The site groundwater $\mathrm{pH}$ (upstream) is always acidic ( $\mathrm{pH}$ ranges from 3.2 to 4.2 with an average of 3.7), which varies greatly depending on (i) the dilution by large rainfall events and (ii) flushing of acid by small rainfall events following dry periods. Highly aerobic groundwater predicted by high Oxidation and Reduction (ORP) value (up to $530 \mathrm{mV}$ ) and dissolved oxygen ( up to $5 \mathrm{mg} / \mathrm{l}$ ), and low ratio of chloride to sulphate of approximately 0.3 observed in groundwater of up gradient are the indication of continuous pyrite oxidation in the study area. After installation of PRB, the groundwater inside the barrier has become alkaline to neutral $(\mathrm{pH} 10.2$ to $\mathrm{pH} 7.3)$ with respect to time under the field condition (Figure 5). Both the dissolved oxygen and ORP have decreased dramatically inside the PRB and have been maintained to $<0.2 \mathrm{mg} / \mathrm{l}$, and negative to small positive values in all the wells of PRB respectively during the study period, indicating that the reducing condition is strongly dominant for the dissolution of limes from the reactive media. Downstream to the $\mathrm{PRB}$, the $\mathrm{pH}$ has been improved significantly up to $\mathrm{pH} 6.2$ due to dilution of the existing acidic water by the effluent from PRB. However, the lower $\mathrm{pH}$ in the downstream as compared with that in PRB is due to time to time mixing of acid generated in the soil by pyrite oxidation. 

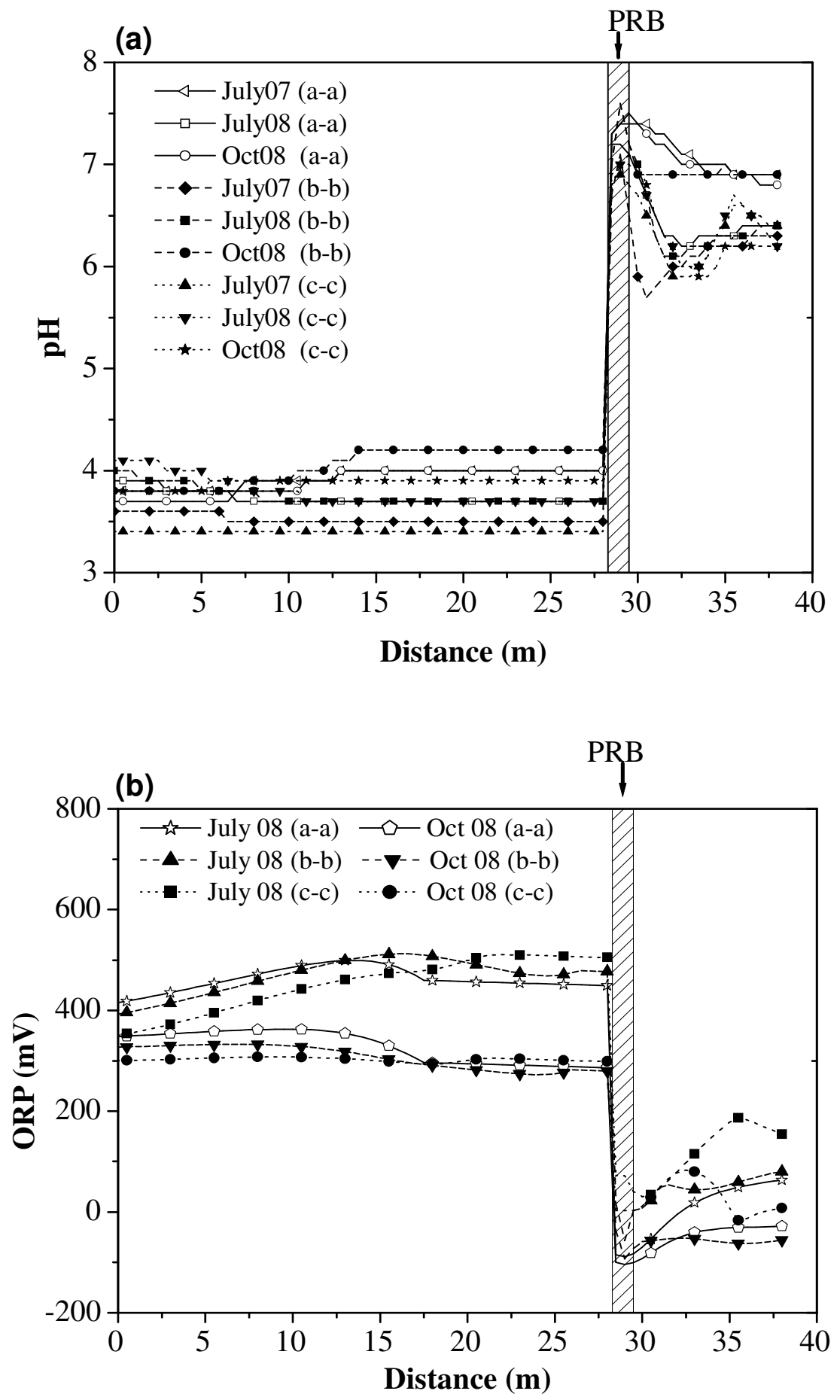


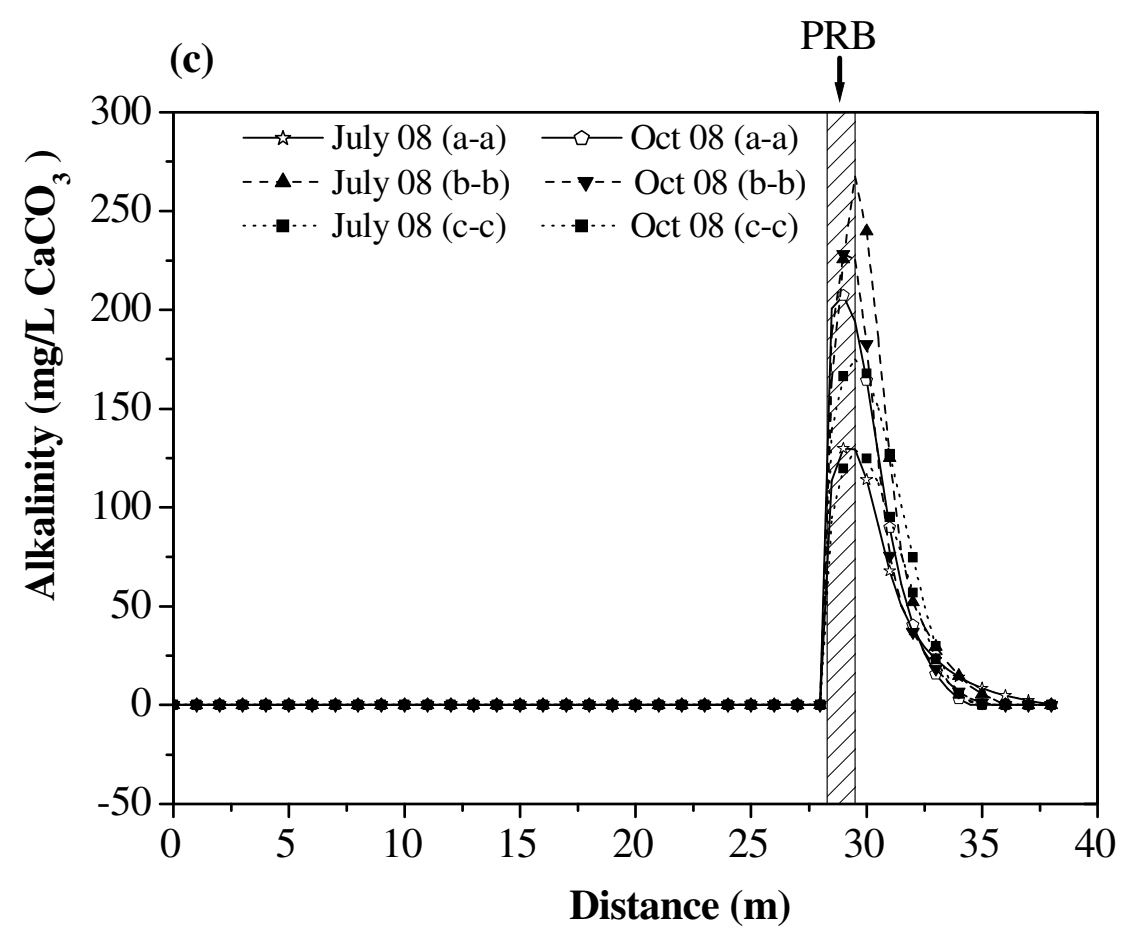

Figure $4 \mathbf{~ a ~ p H , ~ b ~ O R P ~ a n d ~} \mathbf{c}$ alkalinity profiles along an estimated groundwater flow direction crossing the PRB at three different sections

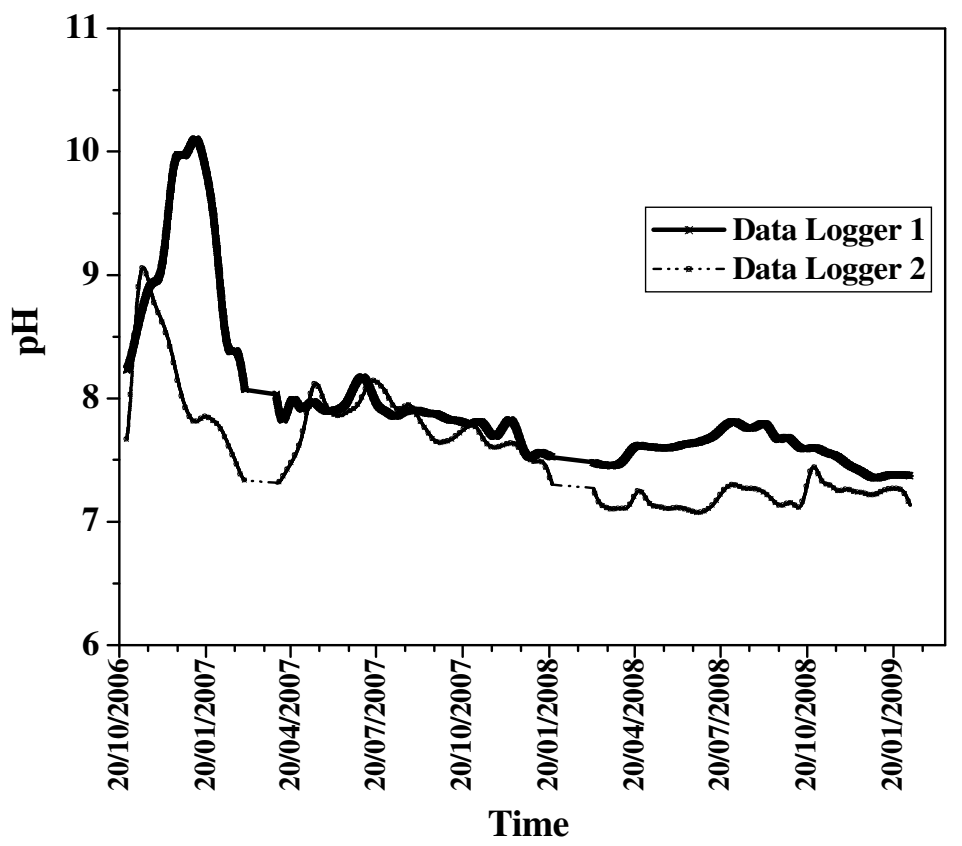

Figure 5 Temporal variation of $\mathrm{pH}$ in the data-loggers installed inside the PRB (section b-b and c-c) 
In addition, analysis of concentrations of cations and anions of groundwater samples indicate that solids precipitates might have been formed within the pore space of the PRB. Negligible change in the concentration of sodium, chloride, potassium and magnesium concentrate inside the PRB from the upstream concentrations in different times indicates that these common ions in the aquatic environment are not affected by the neutralization reaction of the lime present in the concrete of PRB. However, the increase in calcium concentration from 50 - $125 \mathrm{mg} / \mathrm{L}$ upstream to $225-300 \mathrm{mg} / \mathrm{L}$ at different sections at different time intervals indicate that lime dissolution rate has been consistently maintained at $200 \mathrm{mg} / \mathrm{L}$ inside the PRB, thus well maintaining the $\mathrm{pH}$ to nearly neutral (Figure 6a).

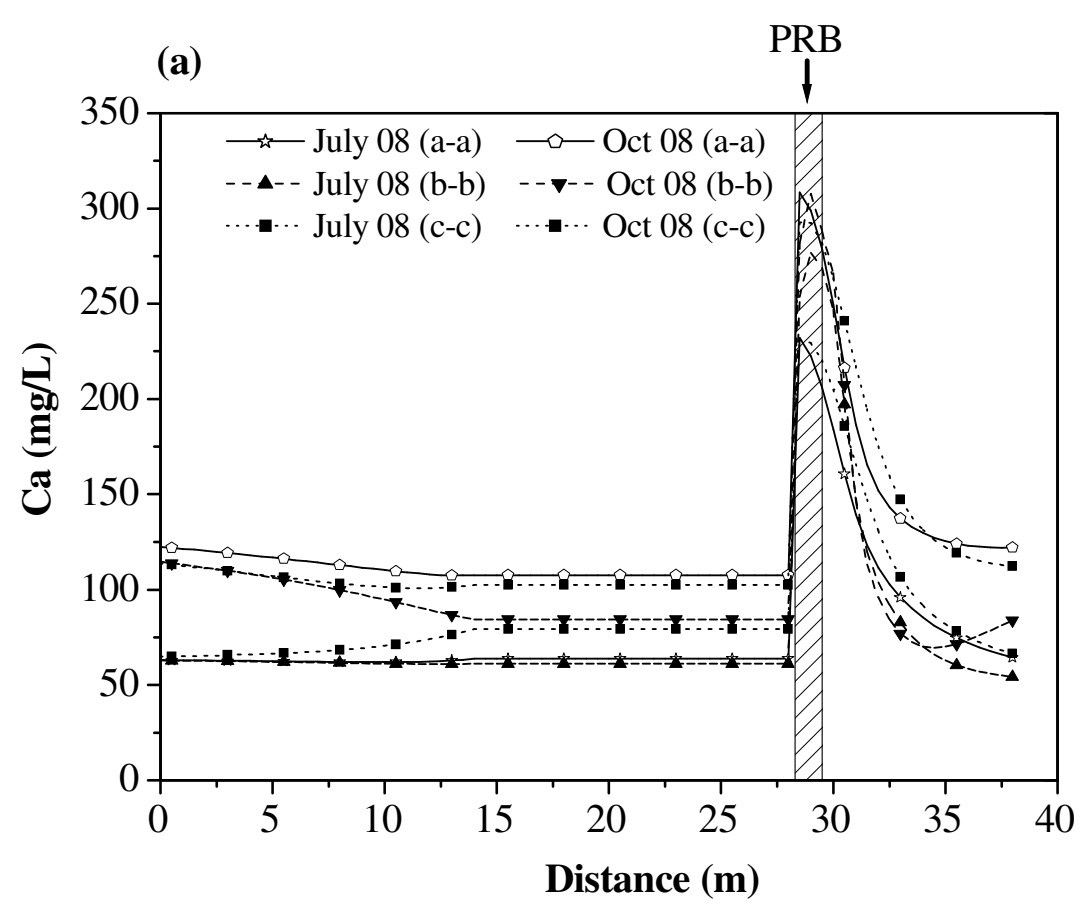



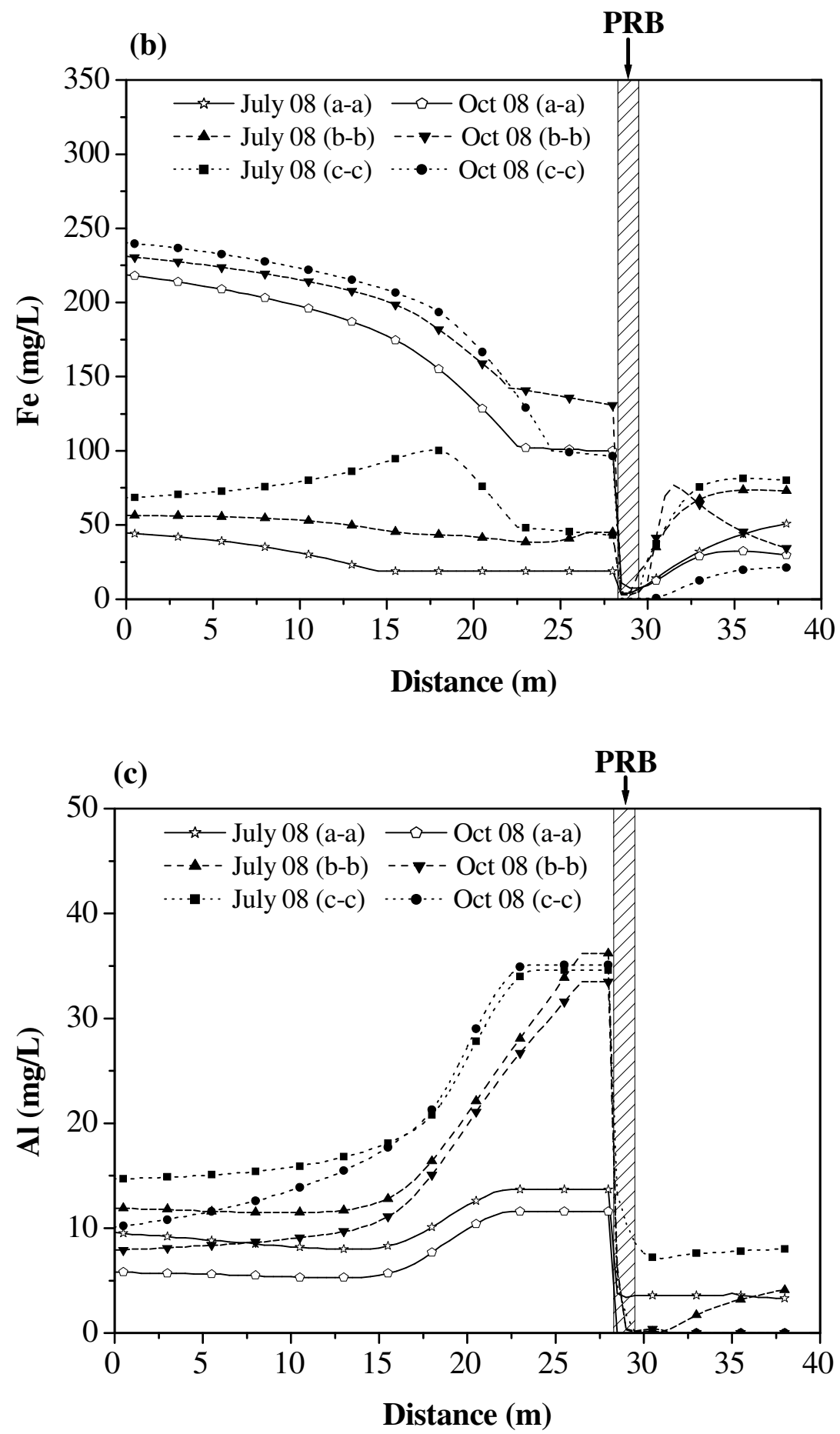


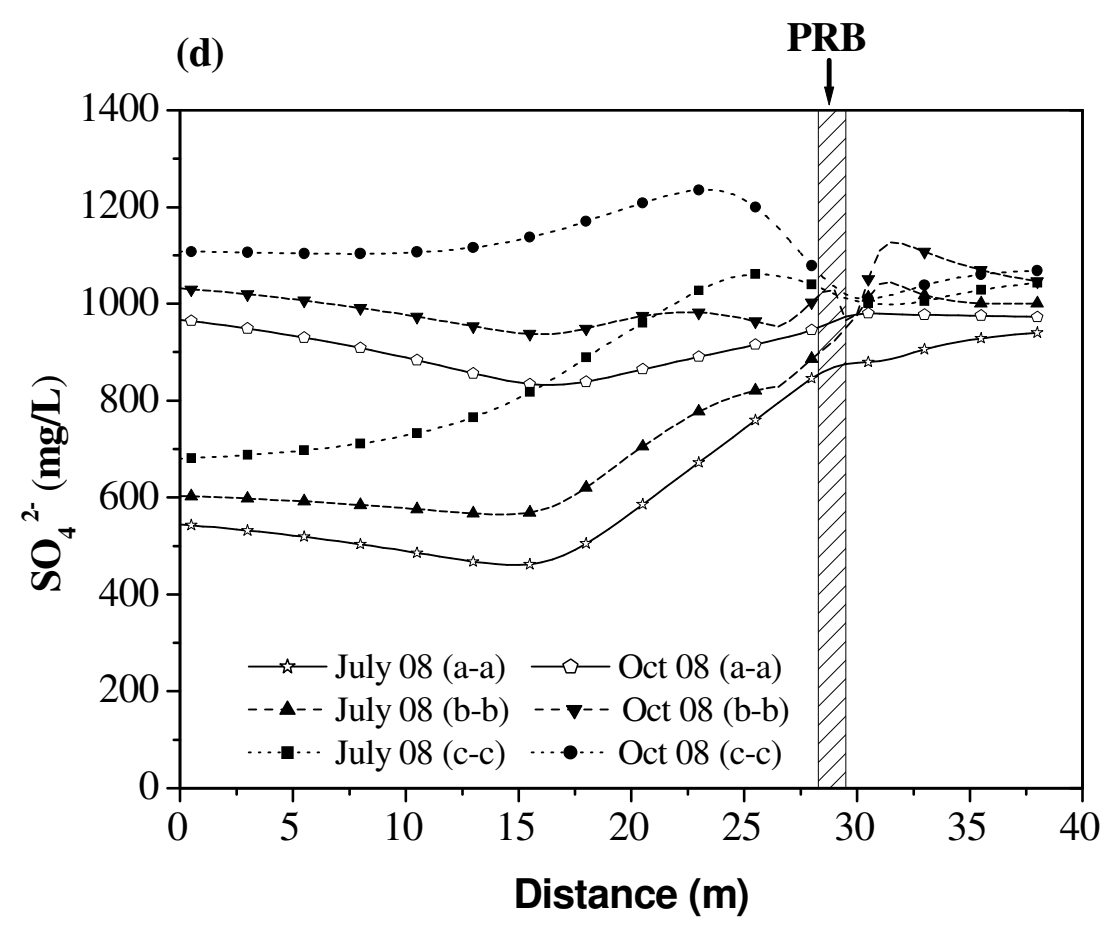

Figure 6 Results of chemical analysis for selected ions: a calcium $\mathbf{b}$ iron $\mathbf{c}$ aluminium $\mathbf{d}$ sulphate profiles along an estimated groundwater flow direction crossing the PRB at three different sections

The cementetious materials in the recycled concrete contains large amount of calcium (Table 1) in different complex forms of calcium minerals such as calcium silicate hydrated compounds (C-S-H), calcium alumiatesilicate hydrated compounds (C-A-H) and lime. Dissolution of these minerals in presence of moisture has the potential to generate large amount of calcium hydroxide which has a capacity to react with acid as shown in equation 6 to improve the $\mathrm{pH}$ of the pore water to near neutral, releasing large amount of calcium. Furthermore, rapid fall in iron and aluminium concentrations inside the PRB indicate that the reactions outlined in Eqs 7 to 10 might have occurred after the dissolution of calcium and hydroxide ions from the concrete. The temporary increase in $\mathrm{pH}$ has speeded up the subsequent precipitation of iron and aluminium as hydroxides and oxyhydroxides. As a result, the alkalinity provided by the PRB is consumed and the $\mathrm{pH}$ has dropped once more. Figures $6 \mathrm{~b} \& \mathrm{c}$ summarize treatment efficiency of recycled concrete in relation to iron and aluminium precipitation. The removal of iron and aluminium is extremely impressive, 
decreasing the higher values of $150 \mathrm{mg} / \mathrm{L}$ and $30 \mathrm{mg} / \mathrm{L}$ respectively in the upstream acidic water adjacent to PRB to very low value $(<5 \mathrm{mg} / \mathrm{L})$ inside the PRB.

Compared with the upstream values of these metals, the removal efficiencies are still greater than $95 \%$. However, iron and aluminium concentrations in the downstream are higher and they sometimes have reached nearly the upstream values at some monitoring wells, depending on the dilution of the initially stored ions and further pyrite oxidation in the soils of that area.

From the sulphate profile, it has been cleared that although large amounts of sulphates have been produced during acid production, recycled concrete is not as effective as initially thought in removing sulphate ions. Such sulphate from acidic groundwater might have "sulphate effect" on the concrete at the interface of the upstream zone and PRB leading to the extensive decomposition of hydrated calcium silicate and lime and generation of alkalinity. However, possible increase in permeability by this attack is beneficial to some extend for preventing the chemical clogging by the precipitates occurring at that zone. But, the effluent from PRB in downstream has near neutral $\mathrm{pH}$ and the presence of calcium and sulphate ions are not harmful at near neutral $\mathrm{pH}$ because gypsum has been popularly used as inorganic fertilizer in agricultural farm.

In order to confirm these precipitation chemical reactions, equilibrium modelling has been carried out using PHREEQC (USGS Code). Speciation calculation in the equilibrium modelling for upstream groundwater indicates that small amount of goethite $[\mathrm{FeOOH}]$ and large amount of hematite $\left[\mathrm{Fe}_{2} \mathrm{O}_{3}\right]$ are precipitated in the upstream due to oxidation of Ferric ions in the aerobic zone. In addition, the model also suggest the precipitation of alunite $\left[\mathrm{KAl}_{3}(\mathrm{SO} 4)_{2}(\mathrm{OH})_{6}\right]$, but in small amounts due to less concentration of potassium in water. On the other hand, positive values of the saturation index (SI) of aluminium and iron minerals 
such as gibbsite $\left[\mathrm{Al}(\mathrm{OH})_{3}\right]$, goethite $[\mathrm{FeOOH}]$ and siderite $\left[\mathrm{FeCO}_{3}\right]$ obtained in the water from PRB indicate that small amount of iron and aluminium are still precipitating, although their large amounts have already precipitated during the neutralization reaction with dissolved lime from concrete. However, the speciation calculation of the equilibrium modelling could not predict the minerals that were deposited by chemical reaction. To confirm the assumption of the possible neutralization reaction for precipitation of iron and aluminium as described in Eqs 7 to 13, inverse geochemical modelling has been carried out considering all the possible minerals phases obtained in the speciation calculation of the water sample upstream to PRB and inside the PRB. The results of phase mole transfer of different minerals for precipitation/ dissolution mechanism in inverse geochemical modelling (Table 3) confirms the precipitation of iron and aluminium in different forms of hydroxides and oxyhydroxides and carbonates verifying the assumptions of the possible reactions described in Eqs 7 to 13. 
Table 3 Phase mole transfer of minerals from inverse geochemical modelling

\begin{tabular}{|c|c|c|c|}
\hline \multirow{2}{*}{ Minerals } & \multirow{2}{*}{ Chemical Formula } & \multicolumn{2}{|c|}{ Phase mole transfer } \\
\cline { 3 - 4 } & & minimum & Maximum \\
\hline $\mathrm{Al}(\mathrm{OH})_{3}$ & $\mathrm{Al}(\mathrm{OH})_{3}$ & $-7.51 \times 10^{-4}$ & $-4.57 \times 10^{-4}$ \\
\hline Alunite & $\mathrm{KAl}_{3}(\mathrm{SO} 4)_{2}(\mathrm{OH})_{6}$ & $-2.73 \times 10^{-4}$ & $-1.27 \times 10^{-4}$ \\
\hline Anhydrite & $\mathrm{CaSO}_{4}$ & $-1.04 \times 10^{1}$ & $-6.58 \times 10^{0}$ \\
\hline Aragonite & $\mathrm{CaCO}_{3}$ & $-1.54 \times 10^{1}$ & $+8.55 \times 10^{-3}$ \\
\hline Calcite & $\mathrm{CaCO}_{3}$ & $-1.54 \times 10^{1}$ & $+8.55 \times 10^{-3}$ \\
\hline Dolomite & ${\mathrm{CaMg}\left(\mathrm{CO}_{3}\right)_{2}}_{2}$ & $-9.5 \times 10^{-4}$ & $-9.47 \times 10^{-3}$ \\
\hline Fe$(\mathrm{OH})_{3}$ & ${\mathrm{Fe}(\mathrm{OH})_{3}}_{2}$ & $-3.47 \times 10^{-3}$ & $-2.89 \times 10^{-7}$ \\
\hline Gibbsite & ${\mathrm{Al}(\mathrm{OH})_{3}}_{2}$ & $-6.23 \times 10^{-4}$ & $-1.10 \times 10^{-4}$ \\
\hline Goethite & $\mathrm{FeOOH}_{2}$ & $-3.47 \times 10^{-3}$ & $-2.89 \times 10^{-7}$ \\
\hline Gypsum & $\mathrm{CaSO}_{4}: 2 \mathrm{H}_{2} \mathrm{O}$ & $+6.58 \times 10^{0}$ & $+1.04 \times 10^{1}$ \\
\hline Halite & $\mathrm{NaCl}_{2}$ & $+3.89 \times 10^{-3}$ & $+5.57 \times 10^{-3}$ \\
\hline Hematite & $\mathrm{Fe}_{2} \mathrm{O}_{3}$ & $-1.74 \times 10^{-3}$ & $-1.45 \times 10^{-7}$ \\
\hline Siderite & $\mathrm{FeCO}_{3}$ & $-3.37 \times 10^{-3}$ & $-7.64 \times 10^{-4}$ \\
\hline
\end{tabular}

\subsection{Performance of the PRB and Longevity}

The long- term success of PRB depends on the physical and chemical properties of barrier materials. Potential barrier materials should maintain a reactive surface and permeability for a long time. The performance of the current PRB for two and half years is illustrated by the comparative study of spatial distribution of groundwater $\mathrm{pH}$, alkalinity, calcium, iron and aluminium at three different sections and temporal distribution of $\mathrm{pH}$ measured inside the PRB (Figures 4 to 6). When low $\mathrm{pH}$ acidic ground water comes in contact with alkaline materials (recycled concrete), $\mathrm{Ca}^{2+}$ ions are released by the dissolution of the calcite and limes present in recycled concrete. Consequently, alkalinity (i.e. $\mathrm{OH}^{-}$) is increased into the system as well as corresponding $\mathrm{pH}$. Because the concrete used in the barrier was not fully 
saturated in the early phase of installation of $\mathrm{PRB}$, rise in $\mathrm{pH}$ continued from $\mathrm{pH} 7.0$ to $\mathrm{pH}$ 10.0 under field condition due to increase in the rate of lime dissolution until it reached pleatue.

The decrease in the efficiency of the recycled concrete over time is due to fouling of mineral precipitates over the surface and pore space of the materials. Thus, after reaching a peak $\mathrm{pH}$ in fully saturated stage, it started to decrease due to neutralization reaction between acidic water and alkalinity generated into the system, and precipitation of ions such as iron and aluminium could also raise the acidity (Waybrant et al. 2002).

Gradually decreasing rate of $\mathrm{pH}$ inside the $\mathrm{PRB}$ ( $\mathrm{pH}$ value ranging over $\mathrm{pH} 7.5$ after 2.5 years of installation) showing a similar behaviour to the column test results indicates that recycled concrete is a well neutralizing material for acidic water even with occurrence of mineral precipitation.

The improvement in the $\mathrm{pH}$ in the downstream $(\mathrm{pH}>6)$ to a distance of $10 \mathrm{~m}$ downstream from such pilot scale PRB in the field suggests that large scale PRB filled with recycled concrete could successfully control the acidic groundwater of large area in the field. However, the lower $\mathrm{pH}$ in the downstream as compared with that inside the PRB is due to: (i) mixing of the acid that was already stored in the soil, with the effluent, (ii) time to time recharge of acid in groundwater from pyrite oxidation as PRB can not control the acid generation in the soil by pyrite oxidation, and (iii) mixing of upstream groundwater near to the edge of the PRB towards downstream due to small capture zone of pilot scale continuous type of PRB. Nevertheless, the spatial and temporal variation of the $\mathrm{pH}$ clearly indicates that PRB with recycled concrete has been significantly improving the $\mathrm{pH}$ in the down gradient. Because of the uncontrolled pyrite oxidation in soil everywhere including downstream, such 
pilot scales PRBs would function more effectively for large area in ASS terrain if constructed in series at certain spacing.

In addition, constant rate of calcium dissolution from concrete, and excellent rate of aluminium and iron removal efficiency (efficiency >95\%) during the end of two and half year are the indicators to show that PRB is performing well for neutralizing acidic water. Precipitation of iron and aluminium by the neutralization reaction of lime with acidic water is the major removal mechanism of these two metals in the PRB, but has caused significant amount of armouring on the surface of the reactive media, further reducing the efficiency of the material in acid neutralization. As significant drop in $\mathrm{pH}$, and iron and aluminium removal efficiencies have not been observed, it can react for longer periods with no significant change in permeability or pore clogging.

\section{Conclusion}

Subsurface permeable reactive barriers have been used successfully for treating contaminant groundwater such as acidic mine drainage and heavy metals. The selection of the reactive media to be used is of paramount importance, with particular reference to the long term neutralizing capacity and permeability. Performance analysis of the small scale column test in the laboratory shows a significant improvement of groundwater $\mathrm{pH}$ from strongly acidic to nearly neutral level. The operation of the PRB filled with recycled concrete at the site during two and half year periods after installation reconfirmed the column test results.

Monitoring data indicate that the pilot scaled PRB can be effective for maintaining the $\mathrm{pH}$ well above neutral level with great attenuation of the dissolved iron and aluminium from acid sulphate soil groundwater. Geochemical equilibrium modelling of the groundwater in the PRB site confirms that water chemistry is primarily controlled by the dissolution of lime and precipitation of aluminium and iron hydroxides and oxyhydroxides minerals. 
However, the trends of decreasing acid neutralization capacity with increasing iron and aluminium concentration in the wells inside the PRB over two and half year indicates that armouring of the surface of reactive media has occurred because of the fouling of minerals over the surface of recycled concrete and void space, and has further affected the reactivity of the recycled concrete. The steady piezometric head at the current stage of study within the PRB indicates that clogging has not yet affected the groundwater flow characteristics of the PRB. Further longevity of the PRB depends on the acidity production in the soils, amount of dissolved iron and aluminium in the groundwater, remaining reactive surface area left after armouring effects, long term dissolution rate of lime and its initial quantity. Because of continuous precipitation of the iron and aluminium inside the PRB, it is therefore most likely that changes in the hydraulic conditions of the system will be the limiting factors on the barrier's longevity rather than the amount of reactive material in the barrier. Further monitoring is needed to evaluate the long term performance, especially with regard to mineral precipitation and clogging effect.

\section{Acknowledgement}

The authors wish to thank Glenys Lugg from Manildra Group, Bob Rowlan and Andreas Dillmann from University of Wollongong (UOW) for their assistance with this work. Assistance of Dr. Alexandra Golab (formally at UOW) is gratefully appreciated.

\section{References}

Åström, M. (1998). "Mobility of Al, P and alkali and alkaline earth metals in acid sulphate soils in Finland." The Science of The Total Environment, 215(1-2), 19-30.

Åström, M., and Bjorklund, A. (1995). "Impact of acid sulfate soils on stream water geochemistry in western Finland." Journal of Geochemical Exploration, 55(1-3), 163 170. 
Benner, S. G., Blowes, D. W., Gould, W. D., HerbertJr, R. B., and Ptacek, C. J. (1999). "Geochemistry of a permeable reactive barrier for metals and acid mine drainage." Environmental Science \& Technology, 33, 2793-2799.

Blowes, D. W., Ptacek, C. J., Benner, S. G., McRae, C. W. T., Bennett, T. A., and Puls, R. W. (2000). "Treatment of inorganic contaminants using permeable reactive barriers." Journal of Contaminant Hydrology, 45(1-2), 123-137.

Blowes, D. W., Ptacek, C. J., and Jambor, J. L. (1997). "In-situ remediation of Cr(VI)contaminated groundwater using permeable reactive walls: Laboratory studies." Environmental Science and Technology, 31(12), 3348-3357.

Blunden, B., Indraratna, B., and Nethery, A. (1997). "Effect of groundwater table on acid sulphate soil remediation." GeoEnvironment 97, Bouazza, Kodikara, and Parker, eds., Balkema, Rotterdam, 549-554.

Blunden, B. G., and Indraratna, B. (2000). "Evaluation of surface and groundwater management strategies for drained sulfidic soil using numerical simulation models." Australian Journal of Soil Research, 38, 569-590.

Dent, D. (1992). "Reclamation of acid sulphate soils." Advances in Soil Science, 17, 79-122.

Gavaskar, A. R., Gupta, N., Sass, B. M., Janosy, R. J., and O'Sullivan, D. (1998). Permeable Barriers for Groundwater Remediation: Design, Construction, and Monitoring, Battelle Press, Columbus.

Glamore, W., and Indraratna, B. "The impact of floodgate modifications on water quality in acid sulphate soil terrains." 15th Australasian Coastal and Ocean Engineering Conference Proceedings, Gold Coast, Australia, 265-270.

Glamore, W., and Indraratna, B. (2004). "A two-stage decision support tool for restoring tidal flows to flood mitigation drains affected by acid sulphate soil: case study of 
Broughton Creek Floodplain, New South Wales, Australia." Australian Journal of Soil Research, 42, 639-648.

Golab, A. N., Peterson, M. A., and Indraratna, B. (2006). "Selection of potential reactive materials for a permeable reactive barrier for remediating acidic groundwater in acid sulphate soil terrains." Quarterly Journal of Engineering Geology and Hydrogeology, 39, 209-223.

Gu, B., Watson, D. B., Phillips, D. H., and Liang, L. (2002). "Biogeochemical, mineralogical, and hydrological characteristics of an iron reactive barrier used for treatment of uranium and nitrate." Handbook of Groundwater Remediation Using Permeable Reactive Barriers: Applications to Radionuclides, Trace Metals, and Nutrients, D. L. Naftz, S. J. Morrison, C. C. Fuller, and J. A. Davis, eds., Academic Press, San Francisco, 305-342.

Indraratna, B., and Blunden, B. (1999). "Nature and properties of acid sulphate soils in drained coastal lowland in NSW." Australian Geomechanics Journal, 34(1), 61-78.

Indraratna, B., Golab, A., Glamore, W., and Blunden, B. (2005). "Acid sulphate soil remediation techniques on the Shoalhaven River Floodplain, Australia." Quarterly Journal of Engineering Geology and Hydrogeology, 38, 129-142.

Indraratna, B., Golab, A. N., and Banasiak, L. J. (2006). "Installation of a lime injection barrier for the remediation of acid sulphate soil problems." Quarterly Journal of Engineering Geology and Hydrogeology, 39, 391-401.

Mackenzie, P. D., Horney, D. P., and Sivavec, T. M. (1999). "Mineral precipitation and porosity losses in granular iron columns." Journal of Hazardous Materials, 68(1-2), 1-17. 
McMahon, P. B., Dennehy, K. F., and Sandstrom, M. W. (1999). "Hydraulic and geochemical performance of a permeable reactive barrier containing zero-valent iron, Denver Federal Center." Ground Water, 37(3), 396-404.

Mulvey, P. "Pollution, prevention and management of sulfuric clays and sands." Proceedings of the National Conference on Acid Sulfate Soils, Coolangatta, Queensland, 116-129.

Puls, R. W., Paul, C. J., and Powell, R. M. (1999). "The application of in situ permeable reactive (zero-valent iron) barrier technology for the remediation of chromatecontaminated groundwater: a field test." Applied Geochemistry, 14(8), 989-1000.

Sammut, J., White, I., and Melville, M. (1994). "Stratification in acidified coastal floodplain drains." Wetlands (Australia), 13, 49-64.

Scherer, M. M., Richter, S., Valentine, R. L., and Alvarez, P. J. J. (2000). "Chemistry and microbiology of permeable reactive barriers for in situ groundwater clean up." Critical Reviews in Microbiology, 26(4), 221-264.

Singer, P. C., and Stumm, W. (1970). "Acidic mine drainage: the rate-determining step." Science(167), 1121.

Stumm, W., and Morgan, J. J. (1970). Aquatic Chemistry, John Wiley and Sons, Inc., New York.

Sun, Q., McDonald, L. M., Jr., and Skousen, J. G. "Effects of armouring on limestone neutralization of AMD." West Virginia Surface Mine Drainage Task Force Symposium, Morgantown, WV.

Vogan, J. L., Focht, R. M., Clark, D. K., and Graham, S. L. (1999). "Performance evaluation of a permeable reactive barrier for remediation of dissolved chlorinated solvents in groundwater." Journal of Hazardous Materials, 68(1-2), 97-108. 
Waite, D. T., Desmier, R., Melville, M., Macdonald, B., and Lavitt, N. (2002). "Preliminary investigation into the suitability of permeable reactive barriers for the treatment of acid sulfate soils discharge." Handbook of Groundwater Remediation Using Permeable Reactive Barriers: Applications to Radionuclides, Trace Metals, and Nutrients, D. L. Naftz, S. J. Morrison, C. C. Fuller, and J. A. Davis, eds., Academic Press, San Francisco, 67-104.

Waybrant, K. R., Ptacek, C. J., and Blowes, D. W. (2002). "Treatment of mine drainage using permeable reactive barriers: column experiments." Environmental Science \& Technology, 36(6), 1349-1356.

White, I., Melville, M. D., Wilson, B. P., and Sammut, J. (1997). "Reducing acidic discharges from coastal wetlands in eastern Australia." Wetlands Ecology and Management, 5(1), $55-72$. 


\section{List of Tables:}

Table 1: Elementary analysis of major elements in recycled concrete.

Table 2: Comparison of water chemistry of real ASS groundwater and synthetic water for column test.

Table 3: Phase Mole Transfer of minerals from inverse geochemical modelling (+ sign:

Dissolution, - sign: Precipitation)

\section{List of figure captions:}

Figure 1: Column test experiment set up.

Figure 2: Layout of the PRB in a farm of Acid Sulphate Terrain in southeast New South Wales.

Figure 3: Longevity study of recycled concrete with medium flow rate of $2 \mathrm{~mL} / \mathrm{min}$ in column test experiment.

Figure 4: (a) $\mathrm{pH}$, (b) ORP and (c) Alkalinity profiles along an estimated groundwater flow direction crossing the PRB at 3 different sections.

Figure 5: Temporal variation of $\mathrm{pH}$ in the data-loggers installed inside the PRB (section b-b and $\mathrm{c}-\mathrm{c})$.

Figure 6: Results of chemical analysis for selected ions: (a) calcium (b) iron (c) aluminium (d) sulphate profiles along an estimated groundwater flow direction crossing the PRB at 3 different sections. 